\title{
The present state of health economics: a critique and an agenda for the future
}

\author{
Peter Zweifel
}

Published online: 6 September 2012

(C) Springer-Verlag 2012

A couple of days ago, I was asked to give an interview concerning the conference ECHE 2012, the motto of which was, "Progress in Health Economics". One of the questions posed to me was, "What is your vision of Health Economics 10 years from now?" Here is what I had to say.

There are two peculiarities of Health Economics that are of concern to me and that I would like to see addressed in the future. One is the often tenuous relationship of the discipline with general economic theory. Take for instance risk adjustment (RA) in health insurance, which has become an industry of its own in the course of the last 30 years [6]. Health economists invariably seek ways to neutralize the risk selection incentives of health insurers. However, RA payments by health insurers are not borne by them but are shifted to the insured under the guise of increased contributions. The analogy with an indirect tax is evident, and any standard Economics textbook will point out that, while an indirect tax is paid by the sellers of a good, it is effectively borne by the consumers (entirely so in the long run). In the case of RA, the low risks are made to pay a contribution in excess of what is justified in view of their risk profile, while high risks receive an indirect subsidy financed by the low risks.

However, the analogy with indirect taxation has two implications. First, as long as RA remains imperfect (i.e., a situation unlike the long-run equilibrium in the case of a good traded on a competitive market), the risk-selection

This is an extended version of the Farewell Address by the Honorary Chairman, ECHE 2012 European Conference on Health Economics, 19-21 July 2012 in Zurich.

P. Zweifel ( $\square)$

Zurich, Switzerland

e-mail: peter.zweifel@econ.uzh.ch incentives of both the insured and the insurers must be targeted. After all, the low risks have an incentive to seek out a health insurer offering them a favorable deal, permitting them to eschew the indirect tax in form of payment into RA. The high risks do the same, selecting the health insurer offering them a low contribution thanks to a maximum cross-subsidy. This may explain why, at least in Switzerland, the volume of RA has not ceased to increase, contrary to expectations that RA would 'wither away' since it neutralizes insurers' risk selection incentives [2], an expectation reminiscent of government 'withering away' in the happy Marxist state. Second, when there are two objectives (neutralizing the incentives for risk selection of the insurer and the insured in a RA context), the Tinbergen rule of economic policy states that two instruments are needed to attain both of them. Therefore, RA is subject to a kind of impossibility theorem precluding a perfect solution. Admittedly, it took me about a decade to recognize this [4]. Without doubt, Health Economics will benefit in the future by reinforcing its ties with general economic theory.

The second peculiarity of Health Economics causing concern is its overly close relationship with national institutions and sponsors of research. This occurred to me for the first time during ECHE 1995 in Stockholm. When roaming between sessions, I noticed that there was hardly any overlap between two camps of delegates (this is also reflected in [7]). One camp comes from countries with a National Health Service (NHS). There, the discussion revolves about cost effectiveness, QALYs, and equity. The other camp is rooted in insurance-based countries; its focus is on risk selection and RA, moral hazard effects, and the production of health. Interestingly, the members of the two camps seem to be quite happy to be among themselves, presumably their reunion helping them to present their research to some national sponsor later.... 
The long shadow of national sponsors became evident a few years later when Friedrich Breyer and I submitted the manuscript of our textbook Health Economics, 1st edn, to the Oxford office of Oxford University Press. After just a few moments, the gentle voice on the phone asked me, "Sir, is this text in any way critical of the UK National Health Service?" I replied, thinking of our rather diffident review of the efficiency reasons advanced for justifying government intervention in the healthcare sector in ch. 5, "Well, at least by implication, this might be so". Whereupon the gentle voice said, "In this case, may I suggest you submit your text to our New York office". Evidently, a big (and allegedly independent) publisher like Oxford University Press is afraid of the pressure the NHS might exert on it.

Some of our discipline's leading scientific journals have their editorial offices in the UK, and it seems that they are influenced by the main sponsor of research into Health Economics in their country as well. Recently, we submitted a piece revolving around the measurement of consumers' willingness to pay for a new diabetes medication to two of these journals [5]. In both cases, one of the referees without any further justification claimed the results of this study to be biased simply because it had been financed by a pharmaceutical company. They neglected the authors' written affirmation that the contract with the sponsor provided for their full independence in conducting the research. Compare this with a study financed by a government agency, such as the NHS of a European country. In this case, no referee would ever think of claiming a bias in the interest of the sponsor, who would be considered as acting in the citizens' interest - as though governments did not cater to their constituencies in their quest to stay in power and public agencies, pursue their own agenda in order to expand their authority, respectively.

This (too) close relationship with national institutions and sponsors also has a heavy influence on health economists' policy advice. The example of RA is again instructive. Any economics textbook will state the "price equal marginal cost" rule early on, emphasizing the inefficiencies that are caused by violations of this rule. And in the event that some consumers are not able to pay the market price, the recommended remedy invariably is, "Do not regulate price but let the market do its work; simply have the government pay a subsidy to those consumers who cannot afford the good". Only in Health Economics is this advice neglected. It would call for risk-based contributions to health insurance because the best estimate of marginal cost is the expected future healthcare expenditure that comes with enrolling an extra individual [8]. Health economists have unquestioningly adopted the mantra that risk-based premiums are unequitable even if combined with means-tested subsidies, neglecting the textbook advice that subsidies rather than premium regulation should be used to achieve equity. Note that community rating of contributions in fact favors well-to-do individuals susceptible to moral hazard, such as university professors who can visit a physician any time they wish. If risk-rated, they would have to pay far more for their health insurance. Conversely, community rating hurts low-skilled employees who do not dare even to leave their workplace to see a physician for fear of losing their job. In view of their modest utilization of healthcare services, their contribution is excessive. This difference in moral hazard effects is neglected by Kifmann and Roeder [3] in their otherwise excellent theoretical analysis of the welfare effects of community rating versus risk-based premiums combined with subsidies.

Rather than pushing the "price equal marginal cost" rule, health economists have been delving into the exciting second-best world of RA. The literature abounds with proposals refining RA schemes, and I myself plead guilty to participating in this game [1], but see also [2]. However, a seemingly innocuous fine-tuning of the RA formula can have unexpected side effects. The adjustment in question is the so-called Beck formula, which includes the dummy variable 'hospitalization during the preceding year' as an indicator of high risk (Swiss healthcare providers have been blocking successfully the transfer of diagnostic data to health insurers). A particular health insurer commissioned me to simulate the effect of the Beck formula on its RA payments for the years 2005-2007. Whereas this insurer had roughly been a zero net contributor, the Beck formula would have caused it to suddenly pay up to $13 \%$ of its premium volume into the RA scheme [4]. Since Swiss social health insurers must not accumulate reserves, the materialization of this latent liability would have driven this particular insurer into insolvency, with all the undesirable consequences for policyholders. An in-depth analysis showed that the cause was not risk selection but previous efforts (hailed by Swiss policy makers who are keen to achieve the cost savings promised by Managed Care) to keep patients out of hospital. The consequence of this laudable initiative is "too few" hospitalizations, a fact which importantly enters the Beck RA formula. Being part of the unpopular Managed Care legislation, the new formula was, however, rejected in a popular referendum held in June 2012. Since the findings reported in [4] are so much against mainstream Health Economics, it would have not been worthwhile even to try to have them published by one of the field journals.

These examples demonstrate the (scientific and welfare) damage that may be caused by the two peculiarities currently characterizing Health Economics, namely its overly loose ties with general economic theory combined with its overly close ties with national institutions and sponsors of 
Health Economics research. Dear delegates, let me encourage you to achieve progress in Health Economics by rectifying both of these weaknesses of our discipline in the years to come!

\section{References}

1. Beck, K., Zweifel, P., Trottmann, M.: Risk adjustment in health insurance and its long-term effectiveness. J. Health Econ. 29(4), 489-498 (2010)

2. Eugster, P., Sennhauser, M., Zweifel, P.: Capping risk adjustment? J. Health Econ. 29(4), 499-507 (2010)

3. Kifmann, M., Roeder, K.: Premium subsidies and social health insurance: substitutes or complements? J. Health Econ. 30(6), 1207-1218 (2012)
4. Schoder, J., Sennhauser, M., Zweifel, P.: Fine-tuning of health insurance regulation - unhealthy consequences for an individual insurer. Int. J. Econ. Bus. 17(3), 313-327 (2010)

5. Sennhauser, M., Zweifel, P.: Ist ein neues Arzneimittel sein Geld wert? Wessen Geld? Submitted for publication in the German special edition of Pharmaco Econ (2012). Also available from the authors as: a new pharmaceutical: is it worth the money? Whose money?

6. Van de Ven, W., Ellis, R.: Risk adjustment in competitive health plan markets. In: Newhouse, J.P., Culyer, A.J. (eds.) Handbook of Health Economics, vol. 1A, pp. 755-845. North-Holland, Amsterdam (2000)

7. Zweifel, P. (ed.): Health, regulation, and the medical profession. Developments in health economics and public policy. Kluwer/ Springer, Boston (1998)

8. Zweifel, P., Breuer, M.: The case for risk-based premiums in public health insurance. Health Econ. Policy Law 1(2), 171-188 (2006) 